\title{
Logistics management skills development: A Zimbabwean case
}

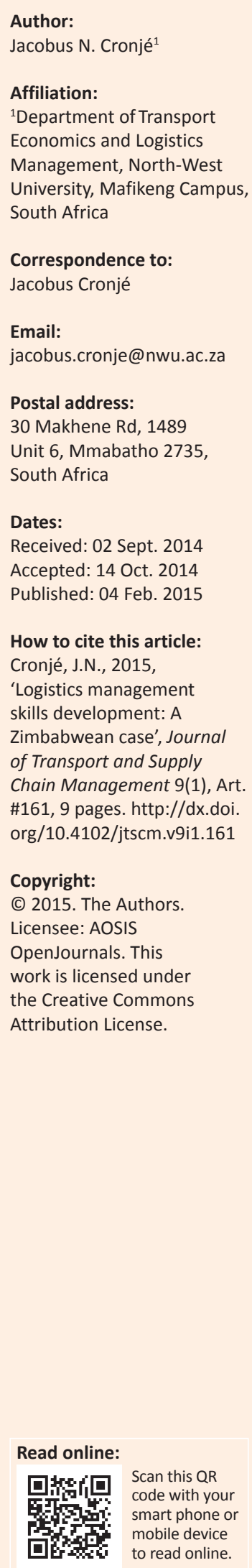

Background: Since logistics emerged as an applied discipline during the latter part of the 20th century, there has been an increased need for skills development in logistics and supply chain management. However, literature suggests a general shortage of educated and skilled logistics and supply chain managers worldwide.

Objectives: The purpose of this article was to benchmark an in-house training programme in logistics management in the beverage industry of Zimbabwe with international best practice.

Method: A case study approach was followed focusing on the programme curriculum, content and delivery. The article reports on the nature and effectiveness of the programme. The curriculum was benchmarked with skills requirements identified in literature. Relevance was evaluated based on participant perceptions over a period of 3 years using questionnaires with both closed- and open-ended questions.

Results: Findings suggested that the programme offering is in line with international practice whilst it also addresses particular issues in Third World countries. Participants perceived the programme as being practical and valuable for enhancing their job performance and career development.

Conclusion: The article provides a framework for evaluating logistics training programmes. Future research could include an evaluation that measures changes in on-the-job behaviour of participants.

\section{Introduction}

Since logistics emerged as an applied discipline during the latter part of the 20th century there has been an increased need for skills development in logistics and supply chain management (SCM). Effective and efficient logistics and SCM contribute to the competitive advantage of companies and supply chains. In fact, logistics has been labelled as a key differentiator in business strategy (Gravier \& Farris 2008). However, literature suggests a general shortage of educated and skilled logistics and supply chain managers worldwide (Dadzi 1998a; Sweeney 2002; Mangan \& Christopher 2005; Heyns \& Luke 2012).

There have been several contributions to the literature on logistics education and training (Dadzi 1998a; Daud, Choon Ling \& Hooi Keoy 2010; Gravier \& Farris 2008; Mangan \& Christopher 2005; Mangan, Gregory \& Lalwani 2001; Kotonen et al. 2011; Sweeney 2002). However, apart from concerns raised by Dadzi (1998b) about the relevance of First World logistics knowledge and education in Third World countries, no evidence could be found of a case study on logistics skills development in African Third World countries.

This research was to a large extent motivated by Mangan and Christophers's (2005) suggestion for further research with regard to: (1) case studies in particular organisations, (2) perceptions of teaching approaches amongst participants on programmes and (3) examining the learning styles and abilities of participants with qualifications on different levels.

The article investigates the nature, relevance and value of a tailored in-company logistics management skills development programme in the beverage industry of Zimbabwe, focusing on middle- and lower-level managers. The research aims to benchmark the programme with international best practice, considering challenges faced by Third World countries as mentioned by Dadzi (1998b).

In an analysis of logistics pedagogical literature, Gravier and Farris (2008) divided the literature into three categories: curriculum (modules that are combined for a programme of study), content (details contained within specific modules) and delivery methods (format and teaching 
strategies). The case study presented in this article reports on all three categories in the Zimbabwean beverage industry.

This article addresses the apparent gap in research regarding the nature and effectiveness of logistics management skills development in individual companies, particularly in Third World countries. Furthermore, it provides a framework for evaluating logistics training programmes.

The remainder of this article is structured as follows. Firstly, the research strategy is discussed, and a profile of the participants is given. Secondly, the curriculum and content are addressed, starting with a detailed review of the literature on skills needs, and discussion and benchmarking of the curriculum of the Zimbabwean programme against findings in the literature. Thirdly, the delivery of the programme is discussed with reference to relevant literature. Fourthly, the relevance and value of the core modules of the programme are evaluated based on participant perceptions within the framework of the Kirkpatrick (1996) approach to programme evaluation. Lastly, conclusions are made and future research is suggested.

\section{Research method and design Research approach}

The main purpose of the study was to benchmark and evaluate the relevance and value of an existing in-house training programme. For this purpose a qualitative case study approach was followed, in order to link theory to the real (empirical) world. Selection of the particular company was mainly based on convenience and purpose. Major considerations were the accessibility of the company and the availability of participants, as a result of the author's involvement in the programme and a long-standing relationship with the company. However, the main consideration was to investigate the relevance and value of the particular programme for the company and its employees.

Literature on skills requirements for logistics and supply chain managers served to benchmark the curriculum and content of the programme. Several items from the pedagogical literature, both general and logistics-specific, were used to compare the programme delivery with best practice. Literature on programme evaluation guided evaluation of the relevance and value of the core modules of the programme.

Data were collected over a period of 3 years using pre-course and post-course questionnaires as research instruments. Prior to commencement of the core modules a structured questionnaire was used to compile a profile of the participants in terms of age, academic qualifications and experience. Participants were also required to list their perceptions of their responsibilities within the company. The post-course questionnaire consisted of closed-and open-ended questions to determine the perceptions of the participants on the relevance of the programme's core modules for their current job and future career, and skills acquired as a result of the programme. Participants were required to rate a number of factors on a five-point Likert scale. The open-ended questions invited them to express their likes and dislikes of the core modules, to propose possible improvements and to list the most valuable things that they learned.

According to Pedrosa, Näslund and Jasmand (2012), a reliable and trustworthy case study should address credibility, dependability, transferability and truth value. The credibility and dependability of this study were addressed by consulting a wide range of literature and by evaluating the programme over 3 consecutive years using the same research instruments. Transferability refers to the extent to which the study's findings can be applied to other contexts or that the study can be generalised. The case study presented here provides a framework for evaluation of similar programmes in other countries or other disciplines. Truth value relates to the extent to which the description and analysis of the case are not the researcher's biased interpretation but reflects the true responses of participants. The data analysed in this case study were compiled using the research instruments. All original responses to questionnaires over the 3-year period are in the possession of the author.

\section{Results and discussion Participant profile}

Over the period of 3 years 24 participants attended the programme, of whom 22 obtained a qualification at a higher education institution, either in the form of a diploma (4 participants), first degree (7), honours degree (4) or master's degree (7). The relatively high academic qualifications confirm that the majority of the participants were exposed to management and business education. The ages of the participants varied from 27 to 58 years. Most of them were quite experienced in terms of exposure to management and business. All of the participants over the 3 years were on a lower- to middle-management level. Work experience varied from 29 to 1.5 years, whilst management experience varied from 10 years to 1 year. However, with the exception of one (who had a diploma in transport management), no participant had any formal distribution, transport, logistics or SCM qualification.

The functional areas in which these managers were employed as well as their opinions of their major responsibilities are summarised in Table 1. Although the extent to which their responsibilities include logistics activities vary, profound knowledge on core logistics aspects appears to be of importance to all functional areas.

\section{Curriculum and content Literature review}

Gammelgaard and Larson (2001) and Mangan and Christopher (2005) suggest that logistics managers require profound knowledge and expertise in the logistics discipline, 
TABLE 1: Participants' functional areas and major responsibilities, as they reported on questionnaire.

\begin{tabular}{|c|c|c|c|}
\hline \multirow[t]{2}{*}{ Functional area of managers and major responsibilities } & \multicolumn{3}{|c|}{ Year and number of participants } \\
\hline & $2011(N=11)$ & $2012(N=6)$ & $2013(N=7)$ \\
\hline Distribution manager & 3 & 2 & 1 \\
\hline $\begin{array}{l}\text { Distribute product through various channels (customers, door-to-door, wholesalers, } \\
\text { third-party distributors, national depots) }\end{array}$ & - & - & - \\
\hline Interaction with manufacturing and plant warehouse & - & - & - \\
\hline Manage fleet and drivers & - & - & - \\
\hline Route planning and scheduling & - & - & - \\
\hline Request resources from top management (such as truck tractors, trolleys, human) & - & - & - \\
\hline Freight or transport manager & 1 & 2 & 1 \\
\hline Daily load planning, routing, scheduling & - & - & - \\
\hline Product allocation to distribution centres from primary warehouse & - & - & - \\
\hline Manpower planning and cost budgeting & - & - & - \\
\hline Rate negotiation with third parties and payment processing & - & - & - \\
\hline Inbound logistics (raw material collection) & - & - & - \\
\hline Regional sales manager & 3 & 0 & 2 \\
\hline Develop and implement marketing strategies to increase sales & - & - & - \\
\hline Ensure efficient customer service & - & - & - \\
\hline Customer business development & - & - & - \\
\hline Customer relationship management & - & - & - \\
\hline Key account management & - & - & - \\
\hline Debtors' management & - & - & - \\
\hline Provide sales budgets, forecasting and planning & - & - & - \\
\hline Training, supervision and leadership of sales teams & - & - & - \\
\hline Meeting sales targets in the right mix and correct channels & - & - & - \\
\hline Manage distribution & - & - & - \\
\hline Compile and control sales and distribution budgets & - & - & - \\
\hline Operations manager & 2 & 0 & 3 \\
\hline Manufacturing, distribution and warehousing & - & - & - \\
\hline Transport management & - & - & - \\
\hline Budgeting & - & - & - \\
\hline Human resources management & - & - & - \\
\hline Debtors' management & - & - & - \\
\hline Distributor development manager & 1 & 0 & 0 \\
\hline Setting up distributors & - & - & - \\
\hline Training on routines to be followed by distributors & - & - & - \\
\hline Monitoring distributor performance & - & - & - \\
\hline Warehouse manager & 1 & 2 & 0 \\
\hline Empties collection, packaging and receipt of final product for the market & - & - & - \\
\hline Interface between packaging and freighting & - & - & - \\
\hline Stock balancing and ensuring availability & - & - & - \\
\hline Inventory planning & - & - & - \\
\hline Budgeting & - & - & - \\
\hline
\end{tabular}

combined with broad knowledge and abilities in other disciplines.

The literature reveals two main approaches to identifying the skills needs of logistics and supply chain managers. The first approach involves surveys using questionnaires or interviews with various stakeholders, such as providers, users, buyers and practitioners (Dadzi 1998a; Gammelgaard \& Larson 2001; Heyns \& Luke 2012; Mangan et al. 2001; Mangan \& Christopher 2005; Murphy \& Poist 2006, 2007; Razzaque \& Bin Sirat 2001). The second approach involves analysing job advertisements and responses from executive recruitment and placement firms for various levels of logistics or supply chain managers (Radovilsky \& Hegde
2012; Radovilsky, Hegde \& Kandasamy 2007; Sodhi, Son \& Tang 2008). Authors using the second approach claim that this one is more appropriate since it reflects the real needs of industry.

The literature classifies the requisite skills for SCM into various categories. A popular classification is the BLM framework (Murphy \& Poist 2007; Razzaque \& Bin Sirat 2001), which suggests that supply chain managers must be proficient in three major areas: business skills, logistics skills and management skills. Radovilsky et al. (2007), Sodhi et al. (2008) and Radovilsky and Hegde (2012) used only two categories of skills, reflecting core SCM and logistics skills on the one hand and general managerial skills on the other. The 
general managerial skills include communication, teamwork, people management, problem solving, negotiating, project management, leadership, and information technology. Heyns and Luke (2012) classified a set of 38 skills into six categories: general management, behavioural or interpersonal, logistics awareness, logistics analytical, logistics information technology and environmental awareness.

The literature study also revealed that different skills are required for different levels of management. Murphy and Poist (2007) focus on senior management levels, whilst Dadzi (1998a), Murphy and Poist (2006), Radovilsky et al. (2007) and Radovilsky and Hegde (2012) compare the skills requirements for entry-, middle- and senior-level supply chain managers. Most authors conclude that there is a definite difference between skills requirements for seniorlevel managers and middle to lower-management levels. There is also an agreement in the literature that logistics and supply chain managers are 'managers first and logisticians second', suggesting much emphasis on managerial skills.

Table 2 provides a summary of the most important skills requirements identified in various studies. Due to different frameworks or classifications used in the literature, the author created the table for the purposes of this research based on skills areas that appeared most often. Also for the purposes of this study, only two skills categories have been used: core logistics skills and general managerial skills. In the studies that involved various management levels, the skills applicable to middle and lower management are indicated in the table.

The profile of the participants in Dadzi's (1998a) research corresponds to a large extent with that of participants in the current study. The average age of respondents in Dadzi's study was approximately 41 years, whilst the average years of education was between 16 and 18 , indicating at least a university or college degree, and many had a master's degree. However, only $5 \%$ of the respondents had a university or college education in logistics. The majority $(70 \%)$ of the managers in Dadzi's work were on lower- and middle-management level, indicating a strong need for courses in (in descending order) inventory management, transportation, quantitative analysis techniques, financial control and computer systems.

Rutner and Fawcet (2005) observed that fast-changing skills requirements for supply chain managers create gaps between industry requirements and academic programmes. The longitudinal studies by Murphy and Poist (2007) and Radovilsky and Hegde (2012) indeed revealed that logistics skills requirements and the emphasis on individual skills are changing over time. For this reason, the skills identified in the recent studies by Radovilsky and Hegde (2012) and Heyns and Luke (2012) are briefly elaborated upon below.

Radovilsky and Hegde (2012) analysed the percentage frequency of the skills appearing in various website advertisements for lower-, middle- and senior-level SCMrelated positions. Inventory management that includes forecasting (appearing in $66 \%$ of lower- and $57 \%$ of middlelevel advertisements), and procurement, including sourcing and supplier management (49\% of lower- and $56 \%$ of middlelevel advertisements), are the most sought-after logistics skills for both lower- and middle-level positions. The study found a substantial difference between the transport and distribution skills required at different levels $(42 \%$ and $24 \%$ of advertisements for lower- and middle-level management positions respectively). Other important logistics skills identified were operations and financial aspects, contract management, supply chain analysis and planning, and information technology. Management skills that appeared most in advertisements were communication skills (76\% for both lower and middle level), team work (70\% for both levels), general analytical skills and problem solving (66\% for lower and $69 \%$ for middle level), leadership ( $47 \%$ and $48 \%$ respectively), knowledge of software systems such as enterprise resource planning (ERP) $(43 \%$ and 60\% for lower and middle-management positions respectively) and project management ( $41 \%$ and $47 \%$ respectively).

In a survey where almost $80 \%$ of respondents consisted of middle- and senior-level managers, Heyns and Luke (2012) identified customer service, the total systems concept ('ability to see the big picture'), inventory management, supply chain cost knowledge, warehousing, supply chain design, transport, procurement and logistics information technology (IT) as the most important logistics skills. Business ethics, ability to plan and prioritise, problem solving, teamwork, communication, business process improvement, decision making, time management, leadership, motivation and negotiation were identified as important managerial skills.

\section{The Zimbabwean curriculum}

The curriculum for the programme in Zimbabwe was developed by senior officials of the company together with a human resources management consultant and a logistics subject matter expert from an academic institution in South Africa. The curriculum is adjusted regularly to provide for constant and rapid changes in the logistics and supply chain environment and concomitant changing skills requirements.

The programme curriculum consists of core logistics modules supplemented with supporting modules, and follows the T-shaped approach suggested by Mangan and Christopher (2005). Details of the course content (topics within each core module) are provided in Table 3. The supporting modules are: Research Methods \& Statistics (including SPSS and MS Project), Human Resources and Industrial Relations for Distribution Managers, Health and Safety for Distribution, Law of Carriage in Zimbabwe, and Strategic Management (introduced in 2013).

Comparing the curriculum and content of the core modules of the Zimbabwean programme with the requisite logistics skills requirements identified in the literature, one can conclude that the curriculum addresses international industry skills needs. Considering the profile of the participants in terms of academic qualifications and experience, the need for core logistics skills is paramount. Bearing in mind the major 


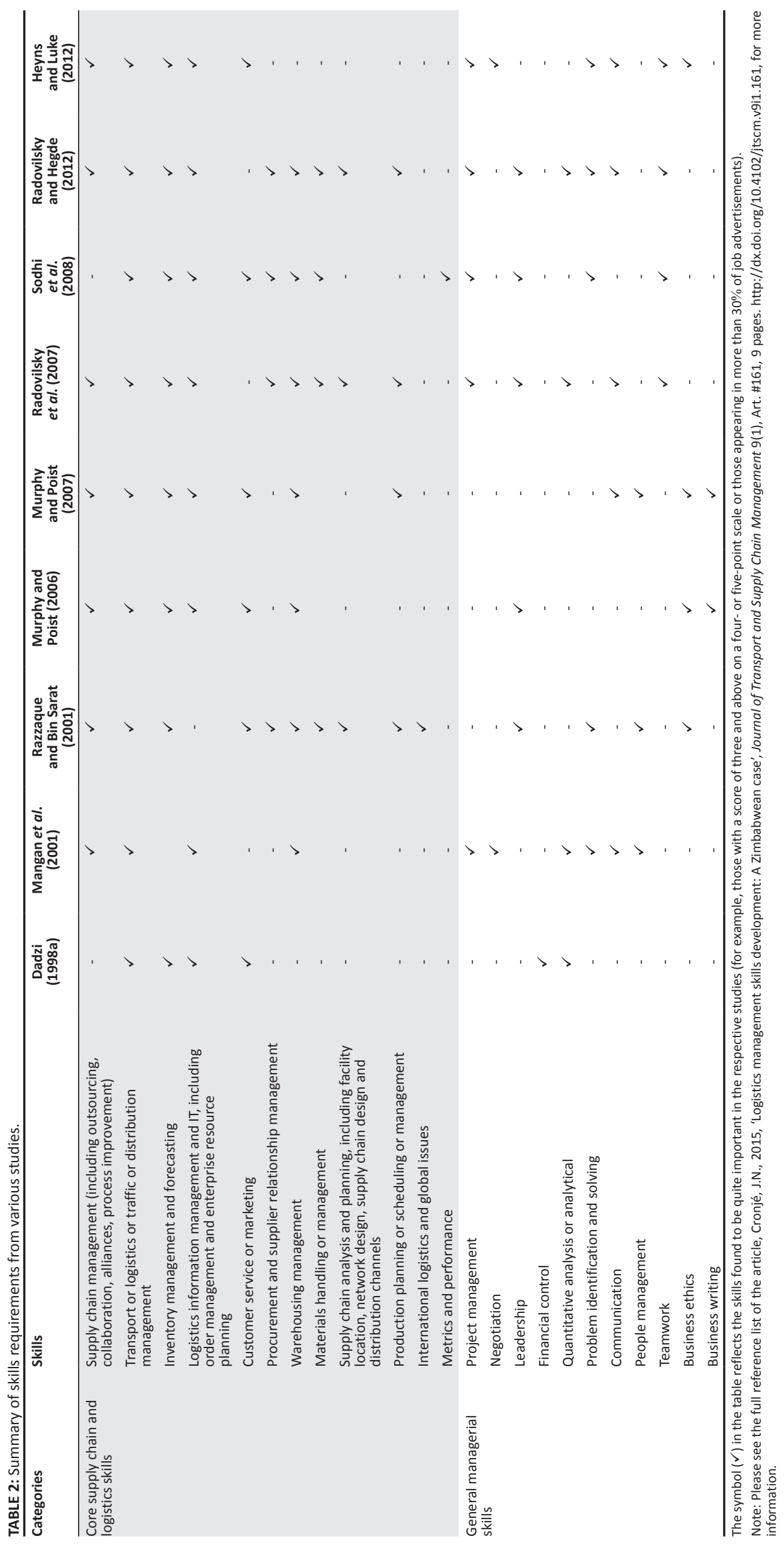


TABLE 3: Programme core modules and content.

\begin{tabular}{|c|c|}
\hline Core modules & Content \\
\hline \multirow[t]{5}{*}{ Customer service } & $\begin{array}{l}\text { Marketing or supply chain management } \\
\text { interface }\end{array}$ \\
\hline & Elements and dimensions of customer service \\
\hline & Cost of customer service \\
\hline & Distribution channels (nature and cost) \\
\hline & $\begin{array}{l}\text { Methods for establishing customer service } \\
\text { strategies }\end{array}$ \\
\hline \multirow[t]{6}{*}{ Inventory management } & Concepts and functions \\
\hline & Inventory ordering and carrying costs \\
\hline & Optimum inventory levels \\
\hline & Alternative inventory systems \\
\hline & Demand forecasting principles and techniques \\
\hline & $\begin{array}{l}A B C \text { inventory classification based on Pareto } \\
\text { ( } 80 / 20 \text { rule) }\end{array}$ \\
\hline \multirow[t]{6}{*}{ Warehouse management } & Warehouse types, functions and benefits \\
\hline & Warehouse layout and planning \\
\hline & $\begin{array}{l}\text { Network planning (location, size and number of } \\
\text { distribution centres) }\end{array}$ \\
\hline & Warehouse operations \\
\hline & Handling systems \\
\hline & Packaging \\
\hline \multirow[t]{8}{*}{ Transport management } & Mode and carrier selection \\
\hline & Carrier negotiation \\
\hline & Fleet planning \\
\hline & Routing and scheduling \\
\hline & Operating efficiency \\
\hline & Transport costs, costing and rates \\
\hline & Budgeting \\
\hline & Investment appraisal \\
\hline \multirow[t]{6}{*}{ Supply chain management } & Supply chain design \\
\hline & Process management \\
\hline & Partnerships and collaboration \\
\hline & Supply chain alignment \\
\hline & Supply chain performance measures \\
\hline & Third- and fourth-party logistics \\
\hline
\end{tabular}

responsibilities of the participants (Table 1), the content of the core modules addresses the gap in their logistics skills. The supporting modules address most managerial skills, research skills, people skills and information and communication technology skills. The curriculum could be adjusted to place more emphasis on ERP systems. However, the company is in the process of implementing SAP as an ERP system, and all users are being trained by the providers of SAP.

\section{Programme delivery}

Kirkpatrick and Kirkpatrick (2009) provide a useful checklist for programme delivery: timing of the programme, venue selection, participant selection, group size, facilitator selection, and teaching strategies. In addition, Mangan et al. (2001), Sweeney (2002) and Gravier and Farris (2008) have identified the type of training (for example, in-house, workshop, on-the-job, college) as an important element of programme delivery.

\section{Type of training}

Dadzi (1998a:260) observes that logistics expertise might be better developed after college or university education, and identified the 'need to explore the relationship between continuing educational needs and the career patterns of current (logistics) practitioners, most of whom had no formal college logistics education'.

Based on their finding that most logistics managers do not possess a logistics or supply chain degree, Gravier and Farris (2008) conclude that these managers benefit greatly from non-degree executive education and coursework as a method of programme delivery. Sweeney (2002) reports on such an executive development programme, focusing on lower- and middle-management levels, and concludes that the success of the programme is attributable to the partnership with industry, ensuring a high academic standard and relevancy to the needs of industry.

Research by Mangan et al. (2001) revealed that in-house training is the second most effective type of training after seminars or workshops. Relevancy was mentioned by respondents as being the major reason for preferring in-house training. The programme in Zimbabwe is offered in-house, using mostly external subject specialists as facilitators.

\section{Timing}

Similar to the executive development programme reported by Sweeney (2002), the programme is offered in blocks, minimising disruption of participants' job responsibilities. The blocks are scheduled with due consideration of the peak periods experienced in the beverage industry.

\section{Venue selection}

Kirkpatrick and Kirkpatrick (2009) state that venue selection should consider travel time, accommodation, and refreshments. The venue for the programme in this study was Mandel Training Centre (MTC) situated in Harare. MTC provides lunch and refreshments for all participants and offers accommodation and meals for participants from outside Harare.

\section{Participant selection and group size}

Participants are selected by their managers to attend the programme. Although not a formal entrance requirement, participants are expected to have obtained a post-school qualification of some nature. Attempts are made to restrict the group size to a maximum of 15 participants.

\section{Facilitator selection}

Gravier and Farris (2008) emphasise the practical relevance of logistics education and the importance of the relationship between academics and industry to ensure relevance. According to Kirkpatrick and Kirkpatrick (2009) knowledge of the subject and the ability to communicate effectively, teach, facilitate and establish rapport with the group are essential qualities of a facilitator. As mentioned earlier, the curriculum was developed by senior officials of the company in consultation with a logistics subject matter expert from an academic institution in South Africa. The subject matter expert was also tasked to facilitate the core logistics modules, whilst the supporting modules are facilitated by specialists in the various disciplines. 


\section{Teaching strategies}

The predominant teaching strategy followed in the Zimbabwean programme is constructivism, which focuses on learning by doing and active learner participation. Such approaches have been well documented in pedagogical literature (Garcia 2006; Lee, McGuiggan \& Holland 2010). Case studies or practical projects in logistics teaching specifically are advocated by Van Hoek (2001), Pal and Busing (2008), Lei Wang (2009) and Cronjé (2011). Van Hoek (2001:513) summarises the advantages of case-based teaching as follows: 'Case teaching not only provides a practical setting, it also allows for an interactive educational experience where professional skills (presenting, analysis) can be trained.' Collaborative learning is addressed widely in general and logistics-specific pedagogical literature (Cronjé 2011; Gudmundsson \& Nijhuis 2001; Van Hoek 2001).

A variety of teaching methods are used for delivering the core modules of the programme in Zimbabwe. These include informal lectures, plenary group discussions, small group discussions and presentations, classroom exercises and activities, and individual and group case studies. Often brief lectures on a topic are followed by a plenary group discussion in the context of the company's activities. These discussions are very valuable in that several problems in the company are identified and participants have the opportunity to share ideas on how to solve them. Since participants are from different departments within the company (such as sales and marketing, warehousing, transport and distribution), the group discussions help them to realise the importance of cross-functional integration, collaboration and information sharing.

Various formative and summative assessment strategies are employed to assess both small groups and individuals. Practical exercises, group discussions and case studies serve as formative assessment instruments. Summative assessment instruments consist of an open-book written test (where participants are assessed individually) and group case studies.

\section{Concerns in Third World countries}

Pedagogical problems raised by Dadzi (1998b) revolve around the lack of foreign currency for textbooks and the lack of adequate library support in Third World countries. To address these concerns comprehensive study material relevant to the core modules is compiled by the facilitator from various sources and provided to MTC before commencement of the programme for distribution to participants. In addition, the facilitator recommends appropriate textbooks to the training centre to add to their collection. On occasion the facilitator also donates books to the MTC.

\section{Relevance and value}

Kirkpatrick (1996:56) argues that programme evaluation is important, to decide whether to continue with a programme, to improve on it and to validate the existence of the institution or individual as a training professional.
Hogan (2007) identifies the CIRO approach (evaluating context, input, reaction and outcomes) as appropriate for evaluation of management training programmes. Very similar to the CIRO approach is the four-level Kirkpatrick's approach (Hogan 2007; Kirkpatrick 1996; Kirkpatrick \& Kirkpatrick 2009) which measures participants' reactions to the programme (satisfaction in terms of topics addressed, facilitators keeping their interest and adhering to schedules), learning (knowledge and skills acquisition), on-the-job behaviour change, and results (such as reduced costs, larger profits or improved quality). Although the value of such an approach is evident, Kirkpatrick (1996) warns that it could become complex to attach a monetary value to training programmes since there are many other variables that may influence company results whilst such evaluation could be quite expensive. For this reason the assessment of relevance and value of the Zimbabwean programme is based on participants' reactions and skills acquisition only.

The core modules of the programme were evaluated in phases over a period of 3 years, using the same research instruments but different participants. Based on a fivepoint Likert-type scale, the participants' reactions to the course delivery and their perception of the value of the core modules in terms of skills acquisition are shown in Table 4. The combined responses of participants were averaged per statement for each year. The questions on course delivery focused mainly on the relevance of the core modules to needs in the workplace, coverage of the course objectives and the facilitator's performance with regard to quality of material and visual aids, preparation, content knowledge, presentation skills, and ability to handle questions, keep the programme on track and engage participants' interest and involvement. It is evident from the results that the reactions of participants were overwhelmingly positive.

The results in terms of skills acquisition indicate that the core modules were of great value, improving participants' performance in the workplace (judged by the average rating for value of the course in helping them to do their job and ability to apply skills acquired in the workplace) and career development. Furthermore, over the 3 years the participants consistently indicated that the modules enhanced their skills to collect, organise, analyse and interpret information, identify and solve problems through critical and creative thinking, and work with others as a team. The team exercises and case studies as well as the plenary group discussions also contributed to collaborative learning, as reflected in the statements on learning from each other.

Responses to the open-ended questions revealed more in-depth reactions and skills acquisition aspects and could be used effectively as indicators for reactions and skills acquisition. Practicality and job relevance were mentioned by the majority of the participants as aspects that they liked most. Exercises, case studies, presentations and ability of the facilitator to use practical examples to ensure understanding of learning material were also mentioned frequently. Under 'dislikes' most respondents expressed their concern about 
TABLE 4: Participant reactions on course delivery.

\begin{tabular}{|c|c|c|c|c|}
\hline \multirow[t]{2}{*}{ Factors } & \multirow[t]{2}{*}{ Variables } & \multicolumn{3}{|c|}{ Year and number of participants } \\
\hline & & $2011(N=11)$ & $2012(N=6)$ & $2013(N=6)$ \\
\hline \multirow[t]{8}{*}{ Course delivery } & Relevance to work needs & 4.5 & 5.0 & 4.5 \\
\hline & Covers course objectives & 4.6 & 4.9 & 4.6 \\
\hline & Quality of material & 4.4 & 4.9 & 4.5 \\
\hline & Facilitator preparation & 4.6 & 4.9 & 4.8 \\
\hline & Facilitator knowledge & 4.8 & 5.0 & 4.9 \\
\hline & Facilitator handling questions & 5.0 & 4.9 & 4.9 \\
\hline & Keeps track & 4.8 & 5.0 & 4.7 \\
\hline & Engages participant interest and involvement & 4.8 & 4.9 & 4.7 \\
\hline \multirow[t]{8}{*}{ Skills acquisition } & Do job & 4.6 & 4.7 & 4.7 \\
\hline & Career development & 4.2 & 4.6 & 4.5 \\
\hline & Collect, organise, analyse and interpret information & 4.5 & 4.7 & 4.5 \\
\hline & $\begin{array}{l}\text { Identify and solve problems through critical and creative } \\
\text { thinking }\end{array}$ & 4.6 & 4.6 & 4.6 \\
\hline & Application in work situation & 4.3 & 4.4 & 4.7 \\
\hline & Work with others as a team & 4.4 & 4.9 & 4.4 \\
\hline & $\begin{array}{l}\text { Learned from others during group discussions and case } \\
\text { studies }\end{array}$ & 4.5 & 4.9 & 4.6 \\
\hline & Others learned from me & 4.2 & 4.3 & 4.2 \\
\hline
\end{tabular}

Averages of responses from participants based on a five-point Likert scale. The evaluation involved core modules only.

TABLE 5: Most valuable topics mentioned in response to an open-ended question.

\begin{tabular}{|c|c|c|c|}
\hline \multirow[t]{2}{*}{ Topic } & \multicolumn{3}{|c|}{ Year and number of participants } \\
\hline & $2011(N=11)$ & $2012(N=6)$ & $2013(N=7)$ \\
\hline $\begin{array}{l}\text { Optimum inventory levels and ordering systems, including forecasting, inventory } \\
\text { carrying costs, just-in-time and logistics requirements planning }\end{array}$ & 8 & 5 & 5 \\
\hline Vehicle routing and scheduling & 8 & 3 & 6 \\
\hline Supply chain management including collaboration and information sharing & 7 & 4 & 5 \\
\hline Transport costs, costing and rates & 6 & 3 & 4 \\
\hline$A B C$ inventory classification & 8 & 2 & 2 \\
\hline Warehousing, facility location and storage systems & 5 & 2 & 2 \\
\hline Investment appraisal & 3 & 2 & 3 \\
\hline Carrier or mode selection, own versus public transport and carrier negotiation & 5 & 1 & 1 \\
\hline Customer service & 0 & 0 & 2 \\
\hline
\end{tabular}

the limited duration ( 3 weeks) reserved for the core modules of the programme. Suggested improvements also focused on increasing the duration of the programme and the number of case studies.

Participants were asked to mention the three most important things that they learned during each of the two blocks of core modules. These topics were classified into nine categories, as shown in Table 5. Optimum inventory levels, routing and scheduling, SCM and transport costing were consistently reported as being valuable topics.

It is evident from these results that despite their relatively high academic qualifications, all participants lacked logistics skills, and the programme contributed immensely in improving these skills. Analysis of the open-ended questions revealed some vital evidence of substantial knowledge gain on core logistics topics. For example, a warehouse manager with an M.Sc. degree in statistics indicated that using normal distribution theory to determine safety stock contributed vastly to his skills. In addition, one of the distribution managers with a diploma in transport management identified inclusion of both fixed and variable transport costs in transport costing as one of the most important things that he learned.

\section{Ethical considerations}

There were no potential physical, psychological or disclosure risks attached to this research. However, informed consent was obtained from the General Manager of MTC, who also consulted with management of the beverage company. Participation was voluntary, but no participant refused or was even hesitant to complete the questionnaires. In addition, the questionnaire on participant perceptions of course delivery and skills acquisition was anonymous.

\section{Limitations of the study}

A limitation of the study could be that the findings related to participant reactions to course delivery and skills acquisition are based primarily on the perceptions of individual participants. However, over a 3-year period participants repeatedly confirmed the skills programme to be extremely relevant and valuable in enhancing their job performance and career development, whilst company management expresses their satisfaction by repeating the programme annually.

Future research could include a comprehensive programme evaluation, including changes in participants' attitudes in 
the workplace (on-the-job behaviour) and improvements in organisational performance in the form of improved productivity, decreased costs or higher profits.

\section{Conclusion}

The article reports on the nature, relevance and value of a tailored, in-company logistics management skills development programme focusing on middle- and lowermanagement levels in the beverage industry of Zimbabwe. Logistics management skills development in terms of curriculum, content and programme delivery is benchmarked against international best practice, with due consideration of the challenges faced by Third World countries.

The lack of formal logistics management qualifications amongst the participants in the case study is indicative of the lack of core logistics management skills in Zimbabwe. Despite most participants having relatively high academic qualifications, the research results suggest that the programme contributes extensively to improvement of their core logistics management skills. The programme curriculum is in line with skills identified for logistics and supply chain managers in the literature on skills needs in the industry. The programme evaluation suggests that it is appropriate and relevant and conforms to the logistics management training needs of the company. However, the programme can be improved by extending its duration to allow for more intense training in certain areas and the inclusion of more case studies.

The programme in its current form could be valuable in other Third World countries where there is an apparent lack of logistics and SCM skills and competency.

This article contributes to the existing literature on case studies in particular organisations and participant perceptions of programme delivery and skills acquisition. Furthermore, the article provides a framework for evaluating logistics training programmes.

\section{Acknowledgements Competing interests}

The author declares that he has no financial or personal relationship(s) that may have inappropriately influenced him in writing this article.

\section{References}

Cronjé, J.N., 2011, 'An integrated approach to teaching and learning logistics: A case study', Journal of Transport and Supply Chain Management 5(1), 53-68.

Dadzi, K.Q., 1998a, 'Management education for physical distribution and logistics', International Journal of Physical Distribution \& Logistics Management 28(4), 259-271.
Dadzi, K.Q., 1998b, 'Transfer of logistics knowledge to third world countries', International Journal of Physical Distribution \& Logistics Management 28(4), 272-283.

Daud, D., Choon Ling, K. \& Hooi Keoy, K., 2010, 'The relationship between logistics programme and logistics educational needs: An exploratory study', International Journal for the Advancement of Science \& Arts 1(2), 28-36.

Gammelgaard, B. \& Larson, P., 2001, 'Logistics skills and competencies for supply chain management', Journal of Business Logistics 22(2), 27-50.

Garcia, A., 2006, 'Combining professional development with academic learning in graduate seminars', Radical Pedagogy: International Consortium for the Advancement of Academic Publication 8(2).

Gravier, M.J. \& Farris, M.T., 2008, 'An analysis of logistics pedagogical literature: Past and future trends in curriculum, content, and pedagogy', International Journal of Logistics Management 19(2), 233-253.

Gudmundsson, S.V. \& Nijhuis, J., 2001, 'Collaborative learning in logistics and transport: The application of 3WIM', International Journal of Physical Distribution \& Logistics Management 31(7/8), 537-556.

Heyns, G. \& Luke, R., 2012, 'Skills requirements in the supply chain industry in South Africa', Journal of Transport and Supply Chain Management 6(1), 53-68.

Hogan, R.L., 2007, 'The historical development of programme evaluation: Exploring the past and present', Online Journal of Workforce Education and Development 2(4), 2-14.

Kirkpatrick, D.L., 1996, 'Great ideas revisited: Revisiting Kirkpatrick's four-level model', Training \& Development 50(1), 54-59.

Kirkpatrick, D.L. \& Kirkpatrick, J.D., 2009, Implementing the Four Levels: A Practical Guide for Effective Evaluation of Training Programmes, Berrett-Koehler Publishers, San Francisco.

Kotonen, U., Tuominen, U., Savonen, M-L., Lahtinen, H. \& Suomäki, A., 2011, 'Skills and competence requirements in logistics centres', Innovations for competence management: International Conference for Educational Organizations and Working Life, Lathi, Finland, 19-20th May.

Lee, G., McGuiggan, R. \& Holland, B., 2010, 'Balancing student learning and commercial outcomes in the workplace', Higher Education Research and Development 29(5), 561-574.

Lei Wang, B.O., 2009, 'To explore teaching mode of logistics system simulation. First international workshop on educational technology and computer science', Education Technology and Computer Science 1, 317-319.

Mangan, J., Gregory, O. \& Lalwani, C., 2001, 'Education, training and the role of logistics managers in Ireland', International Journal of Logistics: Research and logistics managers in Ireland,
Applications 4(3), 313-327.

Mangan, J. \& Christopher, M., 2005, 'Management development and the supply chain manager of the future', International Journal of Logistics Management 16(2), 178-191.

Murphy, P.R. \& Poist, R.F., 2006, 'Skill requirements of contemporary senior- and entry-level logistics managers: A comparative analysis', Transportation Journal 45(3), 46-60.

Murphy, P.R. \& Poist, R.F., 2007, 'Skill requirements of senior-level logisticians: A longitudinal assessment', Supply Chain Management: An International Journa 12(6), 423-431.

Pal, R. \& Busing, M.E., 2008, 'Teaching operations management in an integrated format: Student perception and faculty experience', International Journal of Production Economics 115, 594-610.

Pedrosa, A., Näslund, D. \& Jasmand, C., 2012, 'Logistics case study based research: Towards higher quality', International Journal of Physical Distribution \& Logistics Management 42(3), 275-295.

Radovilsky, Z., Hegde, V.G. \& Kandasamy, G., 2007, 'Development of supply chain management through job market requirements', California Journal of Operations Management 5(1), 52-59.

Radovilsky, Z. \& Hegde, V.G., 2012, 'Trends in supply chain management job requirements: A longitudinal study', Journal of Supply Chain and Operations Management 10(1), 168-181.

Razzaque, M.A. \& Bin Sirat, M.S., 2001, 'Skill requirements: perception of the senior Asian logisticians', International Journal of Physical Distribution \& Logistics Management 31(5), 374-395.

Rutner, S.M. \& Fawcet, S.E., 2005, 'The state of supply chain education', Supply Chain Management Review 9(6), 55-60.

Sodhi, M.S., Son, B. \& Tang, C.S., 2008, 'ASP, the art and science of practice: What employers demand from applicants for MBA-level supply chain jobs and the coverage of supply chain topics in MBA courses', Interfaces 38(6), 469-484.

Sweeney, E., 2002, 'The role of academic/industry partnerships in the development of supply chain managers', paper presented at the Creating Welfare and Prosperity Through Entrepreneurship, 12 th Nordic Conference on Small Business Research, Kuopio, Finland, May 2002.

Van Hoek, R.I., 2001, 'Logistics education: Achieving market and research driven skill development', International Journal of Physical Distribution \& Logistics Management 31(7/8), 505-519. 